\title{
THE EFFECT OF NUTRIENT SOURCES ON GROWTH OF BRADYRHIZOBIUM JAPONICUM AND AZOSPIRILLUM BRASILENSE AT CO-CULTIVATION
}

\author{
Kozar S. F.
}

Institute of Agricultural Microbiology and AgroIndustrial Production NAAS

97, Shevchenko str., Chernihiv, 14027

The paper presents the study of nutrient sources influence on the growth of Bradyrhizobium japonicum and Azospirillum brasilense at their co-cultivation. It was shown that at cultivation of diazotrophs in nutrient media with different concentrations of its components, soybean rhizobia had uneven growth activity. Glucose and molasses was observed to have the greatest impact on the rhizobia count. The results obtained are used as the basis for the optimization of culture medium for co-cultivation of rhizobia and azospirills.

Key words: Bradyrhizobium japonicum, Azospirillum brasilense, growth, nutrients, cultural medium, cultivation.

Beneficial soil microorganisms including rhizobia bacteria used as the agents for different microbial preparations used in modern crop growing technologies play an important role in plant nutrition [1]. The effectiveness of biological preparations highly depends on the titer and functional activity component microorganisms [2]. Thus, it is very important to develop the means that will improve growth activity of diazotrophs ensuring their high nitrogenase activity.

Use of mixed microorganisms' cultures might be one of the ways to enhance the growth of nitrogen fixing bacteria and increase their functional activity. According to our data, and the results obtained by other authors [3,4] creation of biological preparation for soybeans, which would contain nodule bacteria Bradyrhizobium japonicum and associative diazotroph Azospirillum brasilense can be very promising. Thus, at co-inoculation of soybeans with these microorganisms the increase of size and weight of individual nodules on the roots of plants as well as nitogen fixing activity was observed as compared to the pure rhizobia cultures. Co-cultivation of $B$. japonicum and A. brasilense also results in higher growth activity of microorganisms, leading to the higher titer of inoculant. At the same time, different nutrient requirements of rhizobia and azospiryls result in number of problems at medium optimization for co-cultivation of diazotrophs.

Based on the foregoing, our research was aimed to study the effect of different nutrient sources on the growth of Bradyrhizobium japonicum and Azospirillum brasilense in mixed culture.

Materials and methods. Research objects: Bradyrhizobium japonicum M-8 [5], Azospirillum brasilense 18-2 [6], Azospirillum brasilense 410 [7]. All microorganisms were obtained from the National Collection of Useful Soil Microorganisms of Institute of Agricultural Microbiology and AgroIndustrial Production NAAS. 
The number of B. japonicum was determined using cup method by deep inoculation of suspension in agar medium on pea broth [8]. The number of $A$. brasilense was determined using cup method in agar medium, $\mathrm{g} / \mathrm{dm}^{3}$, potato broth -1 , malic acid -3.6 , sucrose -2.5 ; $\mathrm{pH}-7.2-7.4$ (refined with $\mathrm{NaOH}$ solution), agar $-11 \mathrm{~g}$.

Petri dishes were kept in an incubator at $28.0 \pm 2.0^{\circ} \mathrm{C}$. B. japonicum colonies were counted on the tenth day, A. brasilense - on the fourth day.

For co-cultivation the medium with dry yeast, glucose, molasses, $\left(\mathrm{NH}_{4}\right)_{2} \mathrm{SO}_{4}, \mathrm{KH}_{2} \mathrm{PO}$, $\mathrm{K}_{2} \mathrm{HPO}_{4} \cdot 3 \mathrm{H}_{2} \mathrm{O}, \mathrm{MgSO}_{4} \cdot 7 \mathrm{H}_{2} \mathrm{O}, \mathrm{CaCO}_{3}$ was used.

The following variables were studied: (NH4) ${ }_{2} \mathrm{SO}_{4}$ at concentrations of $0.05 \mathrm{~g} / \mathrm{dm}^{3}$ to $3.0 \mathrm{~g} / \mathrm{dm}^{3}, \mathrm{KH}_{2} \mathrm{PO}_{4}-0.01 \mathrm{~g} / \mathrm{dm}^{3}$ to $0.55 \mathrm{~g} / \mathrm{dm}^{3}, \mathrm{~K}_{2} \mathrm{HPO}_{4} \cdot 3 \mathrm{H}_{2} \mathrm{O}-0.01 \mathrm{~g} / \mathrm{dm}^{3}$ to $0.55 \mathrm{~g} / \mathrm{dm}^{3}$, molasses $-1.0 \mathrm{~g} / \mathrm{dm}^{3}$ to $45.0 \mathrm{~g} / \mathrm{dm}^{3}$, glucose - from $2.0 \mathrm{~g} / \mathrm{dm}^{3}$ to $20.0 \mathrm{~g} / \mathrm{dm}^{3}$ yeast feed -1.0 $\mathrm{g} / \mathrm{dm}^{3}$ to $10.0 \mathrm{~g} / \mathrm{dm}^{3}, \mathrm{MgSO}_{4} \cdot 7 \mathrm{H}_{2} \mathrm{O}-0.01 \mathrm{~g} / \mathrm{dm}^{3}$ to $0.5 \mathrm{~g} / \mathrm{dm}^{3}$.

Bacteria were cultivated in $500 \mathrm{~cm}^{3}$ vessels on a shaker with $240 \mathrm{rpm}$ frequency and temperature $28.0 \pm 2.0^{\circ} \mathrm{C}$. B. japonicum and A. brasilense were used at $1: 1$ ratio and cultivated for 72 hours.

Statistical analysis of the experimental data was performed using Statistica 6.0 software package.

Results. Cultivation of rhizobia in nutrient media with different concentrations of its components, had resulted in uneven growth activity of soybean nodule bacteria. Thus, while determining optimal concentrations of nitrogen sources it was revealed that the highest growth activity of $B$. japonicum M-8 was observed at cultivation of microorganisms in the nutrient medium with a mass fraction of $\left(\mathrm{NH}_{4}\right)_{2} \mathrm{SO}_{4}-1.0 \mathrm{~g} / \mathrm{dm}^{3}$ (Table 1). Reduction of the mass fraction diammonium sulfate in the nutrient medium had led to the decrease of $B$. japonicum number. $\mathrm{C} 0$-cultivation of rhizobia with $A$. brasilense 18-2 in the medium with $\left(\mathrm{NH}_{4}\right)_{2} \mathrm{SO}_{4}$ as the nitrogen source with a mass fraction of $0.5 \mathrm{~g} / \mathrm{dm}^{3}, 0.1 \mathrm{~g} / \mathrm{dm}^{3}, 0.05 \mathrm{~g} / \mathrm{dm}^{3}$ the number of B. japonicum M-8 was lower, respectively by $16 \%, 68 \%$ and $92 \%$ compared to the highest obtained number of rhizobia in the experiment. The similar effect on the growth of rhizobia was observed using smaller content of diammonium sulfate co-cultured with $A$. brasilense 410: the number of B. japonicum had decreased by $14 \%, 20 \%$ and $51 \%$ respectively compared to the highest obtained number of these bacteria.

Co-cultivation of B. japonicum M-8 with A. brasilense 18-2 in the nutrient medium with high content of nitrogen had resulted in reduction of the rhizobia number by $8 \%$ (at 1.5 $\mathrm{g} / \mathrm{dm}^{3}$ and $2.0 \mathrm{~g} / \mathrm{dm}^{3}$ ) and $32 \%$ (at $3.0 \mathrm{~g} / \mathrm{dm}^{3}$ ). Joint cultivation of B. japonicum M-8 with $A$. brasilense 410, at higher content of diammonium sulfate the reduction trend of rhizobia number reduction was observed.

While determining the effect of optimal concentration of phosphorus source for microorganisms nutrition it was noticed that the highest growth activity of $B$. japonicum M-8 was observed at their co-cultivation in culture medium with a mass fraction of $\mathrm{KH}_{2} \mathrm{PO}_{4}-0.15$ $\mathrm{g} / \mathrm{dm}^{3}, 0.25 \mathrm{~g} / \mathrm{dm}^{3}$ and $0.35 \mathrm{~g} / \mathrm{dm}^{3}$ (Table 2). 
Table 1. Effect of nitrogen source on the growth of B. japonicum and A. brasilense in liquid nutrient media upon their co-cultivation

\begin{tabular}{|c|c|c|c|c|}
\hline $\begin{array}{c}\text { Concentrations } \\
\left(\begin{array}{c}\left.\mathrm{NH}_{4}\right)_{2} \mathrm{SO}_{4}, \\
\mathrm{~g} / \mathrm{dm}^{3}\end{array}\right.\end{array}$ & $\begin{array}{c}\text { B. japonicum } \\
\text { M-8 }\end{array}$ & $\begin{array}{c}\text { A. brasilense } \\
18-2\end{array}$ & $\begin{array}{c}\text { B. japonicum } \\
\mathrm{M}-8\end{array}$ & $\begin{array}{c}\text { A. brasilense } \\
410\end{array}$ \\
\hline 0,05 & $0,3 \pm 0,12$ & $2,7 \pm 0,30$ & $1,7 \pm 0,15$ & $2,7 \pm 0,15$ \\
\hline 0,1 & $1,2 \pm 0,20$ & $3,5 \pm 0,12$ & $2,8 \pm 0,18$ & $3,0 \pm 0,12$ \\
\hline 0,5 & $3,1 \pm 0,20$ & $3,6 \pm 0,12$ & $3,0 \pm 0,15$ & $3,3 \pm 0,12$ \\
\hline 1,0 & $\mathbf{3 , 7} \pm \mathbf{0 , 1 5 *}$ & $3,8 \pm 0,15$ & $\mathbf{3 , 5} \pm \mathbf{0 , 1 8}$ & $3,7 \pm 0,15$ \\
\hline 1,5 & $3,4 \pm 0,12$ & $3,6 \pm 0,15$ & $\mathbf{3 , 4} \pm \mathbf{0 , 2 1}$ & $3,5 \pm 0,15$ \\
\hline 2,0 & $3,4 \pm 0,20$ & $3,4 \pm 0,15$ & $\mathbf{3 , 3} \pm \mathbf{0 , 1 5}$ & $3,4 \pm 0,15$ \\
\hline 3,0 & $2,5 \pm 0,20$ & $3,4 \pm 0,15$ & $\mathbf{3 , 2} \pm \mathbf{0 , 1 5}$ & $2,7 \pm 0,15$ \\
\hline
\end{tabular}

*Note. The highest number of bacteria (within the limits of experimental error) is highlightened in bold

The data obtained had showed that the highest number of rhizobia were observed at $\mathrm{KH}_{2} \mathrm{PO}_{4}$ concentrations $0.15 \mathrm{~g} / \mathrm{dm}^{3}$ and $0.25 \mathrm{~g} / \mathrm{dm}^{3}$, but upon the increase of salt mass fraction to $0.45 \mathrm{~g} / \mathrm{dm}^{3}$ the titer of B. japonicum M-8 cultured together with A. brasilense 18-2, was reduced by $14 \%$.

The highest titer of B. japonicum M-8, co-cultivated with A. brasilense 410 was seen in the medium containing $\mathrm{KH}_{2} \mathrm{PO}_{4}-0.05 \mathrm{~g} / \mathrm{dm}^{3}, 0.15 \mathrm{~g} / \mathrm{dm}^{3}$ and $0.25 \mathrm{~g} / \mathrm{dm} 3$. Decrease of $\mathrm{KH}_{2} \mathrm{PO} 4$ mass fraction to $0.01 \mathrm{~g} / \mathrm{dm}^{3}$ had resulted in reduction of rhizobia number by $26 \%$, while increasing of its mass fraction to $0.35 \mathrm{~g} / \mathrm{dm}^{3}, 0.45 \mathrm{~g} / \mathrm{dm}^{3}$ and $0.55 \mathrm{~g} / \mathrm{dm}^{3}$ the studied index had decreased, respectively, by $14 \%, 26 \%$ and $34 \%$. Presented data had indicated that co-cultivation of $B$. japonicum M-8 with azospirills, the recommended dose of $\mathrm{KH}_{2} \mathrm{PO}_{4}$ is $0.15 \mathrm{~g} / \mathrm{dm}^{3}$.

Efficiency study of different $\mathrm{K}_{2} \mathrm{HPO}_{4} \times 3 \mathrm{H}_{2} \mathrm{O}$ concentrations had showed that the highest titer of B. japonicum M-8 was observed within the $0.15 \mathrm{~g} / \mathrm{dm}^{3}$ and $0.25 \mathrm{~g} / \mathrm{dm}^{3}$ of dipotassium hydrogen. Both increase or decrease in the content of $\mathrm{K}_{2} \mathrm{HPO}_{4} \times 3 \mathrm{H}_{2} \mathrm{O}$ in the medium, had significantly reduced the titer of rhizobia.

Molasses and glucose were used for determination of the optimum mass fractions of carbon sources in the culture medium. The highest growth activity of $B$. japonicum $\mathrm{M}-8$, cocultured with $A$. brasilense $18-2$ was observed in variants with $10.0 \mathrm{~g} / \mathrm{dm}^{3}, 15.0 \mathrm{~g} / \mathrm{dm}^{3}$ and $20.0 \mathrm{~g} / \mathrm{dm}^{3}$ of molasses (Table 3 ). At this, the rhizobia titer had ranged from 3.6 billion cells / $\mathrm{cm}^{3}$ to 3.7 billion cells $/ \mathrm{cm}^{3}$. 
Table 2. Effect of phosphorus sources on the growth of B. japonicum and A. brasilense in liquid nutrient medium at their co-cultivation

\begin{tabular}{|c|c|c|c|c|}
\hline $\begin{array}{c}\text { Phosphorous } \\
\text { concentrations in } \\
\text { phosphates form, } \\
\text { g/dm }\end{array}$ & $\begin{array}{c}\text { B. japonicum } \\
\text { M-8 }\end{array}$ & $\begin{array}{c}\text { A. brasilense } \\
18-2\end{array}$ & $\begin{array}{c}\text { B. japonicum } \\
\text { M-8 }\end{array}$ & $\begin{array}{c}\text { A. brasilense } \\
410\end{array}$ \\
\cline { 2 - 5 } & \multicolumn{4}{|c|}{$\mathrm{KH}_{2} \mathrm{PO}_{4}$} \\
\hline 0,01 & $0,8 \pm 0,12$ & $2,2 \pm 0,18$ & $2,6 \pm 0,23$ & $2,6 \pm 0,20$ \\
\hline 0,05 & $1,9 \pm 0,18$ & $3,5 \pm 0,09$ & $\mathbf{3 , 4} \pm \mathbf{0 , 0 9}$ & $3,3 \pm 0,09$ \\
\hline 0,15 & $\mathbf{3 , 7} \pm \mathbf{0 , 0 3}$ & $3,7 \pm 0,12$ & $\mathbf{3 , 5} \pm \mathbf{0 , 2 5}$ & $3,6 \pm 0,23$ \\
\hline 0,25 & $\mathbf{3 , 7} \pm \mathbf{0 , 1 5}$ & $3,8 \pm 0,15$ & $\mathbf{3 , 5} \pm \mathbf{0 , 1 8}$ & $3,7 \pm 0,15$ \\
\hline 0,35 & $\mathbf{3 , 5} \pm \mathbf{0 , 1 5}$ & $3,7 \pm 0,15$ & $3,0 \pm 0,09$ & $3,5 \pm 0,18$ \\
\hline 0,45 & $3,2 \pm 0,12$ & $3,6 \pm 0,15$ & $2,6 \pm 0,15$ & $3,0 \pm 0,15$ \\
\hline 0,55 & $2,7 \pm 0,12$ & $3,3 \pm 0,22$ & $2,3 \pm 0,12$ & $3,0 \pm 0,24$ \\
\hline & & $\mathrm{K}_{2} \mathrm{HPO}_{4} \times 3 \mathrm{H}_{2} \mathrm{O}$ & \\
\hline 0,01 & $0,7 \pm 0,15$ & $1,7 \pm 0,24$ & $1,8 \pm 0,12$ & $2,4 \pm 0,18$ \\
\hline 0,05 & $1,6 \pm 0,18$ & $3,5 \pm 0,15$ & $2,7 \pm 0,35$ & $3,1 \pm 0,12$ \\
\hline 0,15 & $\mathbf{3 , 7} \pm \mathbf{0 , 0 7}$ & $3,6 \pm 0,18$ & $\mathbf{3 , 4} \pm \mathbf{0 , 2 6}$ & $3,5 \pm 0,18$ \\
\hline 0,25 & $\mathbf{3 , 7} \pm \mathbf{0 , 1 5}$ & $3,8 \pm 0,15$ & $\mathbf{3 , 5} \pm \mathbf{0 , 1 8}$ & $3,7 \pm 0,15$ \\
\hline 0,35 & $\mathbf{3 , 5} \pm \mathbf{0 , 1 5}$ & $3,7 \pm 0,12$ & $\mathbf{3 , 3} \pm \mathbf{0 , 1 5}$ & $3,6 \pm 0,15$ \\
\hline 0,45 & $3,3 \pm 0,15$ & $3,7 \pm 0,15$ & $2,8 \pm 0,12$ & $3,3 \pm 0,12$ \\
\hline 0,55 & $2,0 \pm 0,09$ & $3,5 \pm 0,17$ & $2,5 \pm 0,15$ & $2,7 \pm 0,17$ \\
\hline & & &
\end{tabular}

Molasses concentration range for B. japonicum M-8 co-cultured with A. brasilense 410 was broad - from $10.0 \mathrm{~g} / \mathrm{dm}^{3}$ to $25.0 \mathrm{~g} / \mathrm{dm}^{3}$, while rhizobia titer had ranged from 3.2 billion cells $/ \mathrm{cm}^{3}$ to 3.5 billion cells $/ \mathrm{cm}^{3}$. Either decrease or increase the mass fraction of molasses in the medium, the number of B. japonicum M-8 had significantly decreased. For all investigated molasses concentrations, the $10.0 \mathrm{~g} / \mathrm{dm}^{3}$ is recommended for rhizobia cocultivation with azospirills. 
Table 3. Effect of carbon source on the growth of B. japonicum and A. brasilense in liquid nutrient medium at their co-cultivation

\begin{tabular}{|c|c|c|c|c|}
\hline \multirow{2}{*}{$\begin{array}{l}\text { Concentration of } \\
\text { carbon source, } \\
\mathrm{g} / \mathrm{dm}^{3}\end{array}$} & \multicolumn{4}{|c|}{ Number of bacteria, billion cells $/ \mathrm{cm}^{3}$} \\
\hline & $\begin{array}{l}\text { B. japonicum } \\
\text { M-8 }\end{array}$ & $\begin{array}{c}\text { A. brasilense } \\
18-2\end{array}$ & $\begin{array}{c}\text { B. japonicum } \\
\text { M-8 }\end{array}$ & $\begin{array}{l}\text { A. brasilense } \\
410\end{array}$ \\
\hline \multicolumn{5}{|c|}{ Molasses } \\
\hline 1,0 & $2,6 \pm 0,17$ & $0,8 \pm 0,15$ & $2,6 \pm 0,20$ & $2,2 \pm 0,20$ \\
\hline 5,0 & $3,0 \pm 0,15$ & $2,9 \pm 0,12$ & $3,1 \pm 0,12$ & $3,0 \pm 0,09$ \\
\hline 10,0 & $3,7 \pm 0,15$ & $3,8 \pm 0,15$ & $3,5 \pm 0,18$ & $3,7 \pm 0,15$ \\
\hline 15,0 & $3,6 \pm 0,07$ & $3,7 \pm 0,18$ & $3,4 \pm 0,18$ & $3,8 \pm 0,15$ \\
\hline 20,0 & $3,6 \pm 0,12$ & $3,7 \pm 0,12$ & $3,4 \pm 0,15$ & $3,6 \pm 0,17$ \\
\hline 25,0 & $3,2 \pm 0,15$ & $3,7 \pm 0,23$ & $3,2 \pm 0,15$ & $3,4 \pm 0,09$ \\
\hline 30,0 & $3,3 \pm 0,12$ & $3,6 \pm 0,15$ & $2,7 \pm 0,15$ & $3,1 \pm 0,12$ \\
\hline 35,0 & $2,6 \pm 0,15$ & $3,4 \pm 0,09$ & $2,2 \pm 0,12$ & $2,3 \pm 0,12$ \\
\hline 40,0 & $2,3 \pm 0,15$ & $2,7 \pm 0,12$ & $2,3 \pm 0,15$ & $2,0 \pm 0,19$ \\
\hline 45,0 & $1,2 \pm 0,24$ & $2,1 \pm 0,21$ & $1,8 \pm 0,17$ & $2,7 \pm 0,15$ \\
\hline \multicolumn{5}{|c|}{ Glucose } \\
\hline 2,0 & $1,7 \pm 0,15$ & $3,4 \pm 0,23$ & $2,1 \pm 0,09$ & $3,4 \pm 0,15$ \\
\hline 4,0 & $2,8 \pm 0,24$ & $3,4 \pm 0,21$ & $2,5 \pm 0,15$ & $3,4 \pm 0,12$ \\
\hline 6,0 & $3,3 \pm 0,18$ & $3,5 \pm 0,20$ & $3,1 \pm 0,12$ & $3,5 \pm 0,12$ \\
\hline 8,0 & $3,5 \pm 0,12$ & $3,4 \pm 0,20$ & $3,4 \pm 0,12$ & $3,5 \pm 0,15$ \\
\hline 10,0 & $3,8 \pm 0,09$ & $3,5 \pm 0,12$ & $3,5 \pm 0,12$ & $3,6 \pm 0,12$ \\
\hline 12,0 & $3,7 \pm 0,15$ & $3,5 \pm 0,21$ & $3,5 \pm 0,18$ & $3,7 \pm 0,15$ \\
\hline 14,0 & $3,7 \pm 0,09$ & $3,3 \pm 0,15$ & $3,5 \pm 0,20$ & $3,5 \pm 0,17$ \\
\hline 16,0 & $3,7 \pm 0,22$ & $3,5 \pm 0,09$ & $3,6 \pm 0,15$ & $3,3 \pm 0,18$ \\
\hline 18,0 & $3,9 \pm 0,09$ & $3,3 \pm 0,09$ & $3,5 \pm 0,15$ & $3,1 \pm 0,17$ \\
\hline 20,0 & $3,9 \pm 0,12$ & $3,2 \pm 0,12$ & $3,4 \pm 0,15$ & $3,1 \pm 0,21$ \\
\hline
\end{tabular}

Rhizobia cultivation in medium with glucose concentrations ranging from $10.0 \mathrm{~g} / \mathrm{dm}^{3}$ to $20.0 \mathrm{~g} / \mathrm{dm}^{3}$, the number of B. japonicum M-8 was at the level of 3.7 billion cells $/ \mathrm{cm}^{3}$ to 3.9 billion cells $/ \mathrm{cm}^{3}$ at co-cultivation $A$. brasilense $18-2$ and from 3.4 billion cells $/ \mathrm{cm}^{3}$ to 3.6 billion cells $/ \mathrm{cm}^{3}$ - with $A$. brasilense 410 . Reduction of glucose content in medium, the number of soybean rhizobia had also reduced. Glucose concentration at $10.0 \mathrm{~g} / \mathrm{dm}^{3}$, is recommended. The increasing of glucose content in the medium is economically unreasonable as the changes of bacteria number was within the error. 
As it was showed in our previous studies it was recommended the use of dry yeasts for co-cultivation of $B$. japonicum M-8 with A. brasilense. Their use is determined by the fact that yeast is rich in proteins as their content can reach $66 \%$, with $10 \%$ of essential amino acids. In addition, yeasts is also a source of growth factors, including vitamins.

Our studies indicate that all investigated concentrations were effective except of 1.0 $\mathrm{g} / \mathrm{dm}^{3}$ and $10.0 \mathrm{~g} / \mathrm{dm}^{3}$ (Table 4) at co-cultivation of rhizobia with A. brasilense 18-2.

Co-cultivation of $B$. japonicum M-8 with $A$. brasilense 410 in medium with glucose concentrations ranging from $3.0 \mathrm{~g} / \mathrm{dm}^{3}$ to $8.0 \mathrm{~g} / \mathrm{dm}^{3}$ had not affected the number of rhizobia, which have stayed within the error. Thus, the economically justified dose of dry yeast was 3 $\mathrm{g} / \mathrm{dm}^{3}$.

Magnesium is required by rhizobia in small amounts for maintenance of bacteria structure and functioning of enzyme systems in microorganism cells. Magnesium - is an essential component of the enzyme ATP-dependent biochemical reactions. It is involved in the metabolism of carbohydrates, proteins and fats, as well as redox reactions. Magnesium activates glycolytic enzymes, enzymes cellular oxidation enzymes synthesis of nucleic acids. Effect of different concentrations of $\mathrm{MgSO}_{4} \times 7 \mathrm{H}_{2} \mathrm{O}$ in nutrient medium on growth activity of diazotrophs was also studied.

Table 4. Effect of dry yeasts on growth of B. japonicum and A. brasilense in liquid nutrient medium at their co-cultivation

\begin{tabular}{|c|c|c|c|c|}
\hline \multirow{2}{*}{$\begin{array}{c}\text { Concentrations, } \\
\mathrm{g} / \mathrm{dm}^{3}\end{array}$} & \multicolumn{4}{|c|}{ Number of bacteria, billion cells / $\mathrm{cm}^{3}$} \\
\cline { 2 - 5 } & $\begin{array}{c}\text { B. japonicum } \\
\text { M-8 }\end{array}$ & $\begin{array}{c}\text { A. brasilense } \\
18-2\end{array}$ & $\begin{array}{c}\text { B. japonicum } \\
\text { M-8 }\end{array}$ & $\begin{array}{c}\text { A. brasilense } \\
410\end{array}$ \\
\hline 1,0 & $3,5 \pm 0,15$ & $3,4 \pm 0,15$ & $2,7 \pm 0,15$ & $3,2 \pm 0,12$ \\
\hline 2,0 & $\mathbf{3 , 8} \pm \mathbf{0 , 1 2}$ & $3,5 \pm 0,20$ & $3,3 \pm 0,09$ & $3,4 \pm 0,15$ \\
\hline 3,0 & $\mathbf{3 , 6} \pm \mathbf{0 , 2 1}$ & $3,6 \pm 0,18$ & $\mathbf{3 , 4} \pm \mathbf{0 , 0 8}$ & $3,5 \pm 0,12$ \\
\hline 4,0 & $\mathbf{3 , 7} \pm \mathbf{0 , 2 3}$ & $3,3 \pm 0,18$ & $\mathbf{3 , 6} \pm \mathbf{0 , 1 2}$ & $3,5 \pm 0,17$ \\
\hline 5,0 & $\mathbf{3 , 7} \pm \mathbf{0 , 1 5}$ & $3,5 \pm 0,21$ & $\mathbf{3 , 5} \pm \mathbf{0 , 1 8}$ & $3,7 \pm 0,15$ \\
\hline 6,0 & $\mathbf{3 , 7} \pm \mathbf{0 , 2 0}$ & $3,5 \pm 0,12$ & $\mathbf{3 , 5} \pm \mathbf{0 , 2 7}$ & $3,3 \pm 0,15$ \\
\hline 7,0 & $\mathbf{3 , 6} \pm \mathbf{0 , 2 2}$ & $3,5 \pm 0,21$ & $\mathbf{3 , 5} \pm \mathbf{0 , 1 2}$ & $3,1 \pm 0,15$ \\
\hline 8,0 & $\mathbf{3 , 6} \pm \mathbf{0 , 1 5}$ & $3,3 \pm 0,21$ & $\mathbf{3 , 4} \pm \mathbf{0 , 2 0}$ & $3,1 \pm 0,23$ \\
\hline 9,0 & $\mathbf{3 , 7} \pm \mathbf{0 , 2 0}$ & $3,3 \pm 0,17$ & $3,3 \pm 0,17$ & $2,8 \pm 0,15$ \\
\hline 10,0 & $3,3 \pm 0,15$ & $3,4 \pm 0,18$ & $3,3 \pm 0,15$ & $2,6 \pm 0,15$ \\
\hline
\end{tabular}


The data presented in Table 5 indicate that the highest number of B. japonicum M-8 cocultivated with $A$. brasilense 18-2 was observed in variants with $\mathrm{MgSO}_{4} \times 7 \mathrm{H}_{2} \mathrm{O}$ concentration ranging from $0.1 \mathrm{~g} / \mathrm{dm}^{3}$ to $0.5 \mathrm{~g} / \mathrm{dm}^{3}$.

Table 5. Effect of $\mathrm{MgSO}_{4} \times 7 \mathrm{H}_{2} \mathrm{O}$ on growth of $\mathrm{B}$. japonicum and A. brasilense in liquid nutrient medium at their co-cultivation

\begin{tabular}{|c|c|c|c|c|}
\hline \multirow{2}{*}{$\begin{array}{c}\text { Concentrations, } \\
\mathrm{g} / \mathrm{dm}^{3}\end{array}$} & \multicolumn{4}{|c|}{ Number of bacteria, billion cells / $\mathrm{cm}^{3}$} \\
\cline { 2 - 5 } & $\begin{array}{c}\text { B. japonicum } \\
\mathrm{M}-8\end{array}$ & $\begin{array}{c}\text { A. brasilense } \\
18-2\end{array}$ & $\begin{array}{c}\text { B. japonicum } \\
\mathrm{M}-8\end{array}$ & $\begin{array}{c}\text { A. brasilense } \\
410\end{array}$ \\
\hline 0,01 & $2,8 \pm 0,15$ & $3,3 \pm 0,15$ & $2,7 \pm 0,17$ & $2,8 \pm 0,24$ \\
\hline 0,05 & $2,9 \pm 0,12$ & $3,6 \pm 0,21$ & $2,6 \pm 0,18$ & $3,4 \pm 0,17$ \\
\hline 0,1 & $\mathbf{3 , 6} \pm \mathbf{0 , 1 5}$ & $3,4 \pm 0,23$ & $\mathbf{3 , 3} \pm \mathbf{0 , 1 2}$ & $3,6 \pm 0,09$ \\
\hline 0,2 & $\mathbf{3 , 5} \pm \mathbf{0 , 2 0}$ & $3,6 \pm 0,20$ & $\mathbf{3 , 5} \pm \mathbf{0 , 1 8}$ & $3,7 \pm 0,15$ \\
\hline 0,3 & $\mathbf{3 , 3} \pm \mathbf{0 , 1 8}$ & $3,5 \pm 0,23$ & $\mathbf{3 , 5} \pm \mathbf{0 , 2 1}$ & $3,5 \pm 0,15$ \\
\hline 0,4 & $\mathbf{3 , 4} \pm \mathbf{0 , 1 8}$ & $3,4 \pm 0,15$ & $\mathbf{3 , 3} \pm \mathbf{0 , 1 2}$ & $3,5 \pm 0,15$ \\
\hline 0,5 & $\mathbf{3 , 3} \pm \mathbf{0 , 2 9}$ & $3,1 \pm 0,27$ & $2,7 \pm 0,15$ & $3,3 \pm 0,17$ \\
\hline
\end{tabular}

It should be noted that use of given component in an amount of $0.1 \mathrm{~g} / \mathrm{dm}^{3}$ is reasonable, as it increases the titer of rhizobia the most. The same concentration of $\mathrm{MgSO} 4 \times$ $7 \mathrm{H} 2 \mathrm{O}$ is recommended for use at co-cultivation of B. japonicum M-8 with A. brasilense 410 since the increasing magnesium content in the medium from $0.1 \mathrm{~g} / \mathrm{dm}^{3}$ to $0.4 \mathrm{~g} / \mathrm{dm}^{3}$ the number of bacteria ad varied but remained within the error.

As a result of our studies the various concentrations of nutrients sources that ensure the maximum growth effect with minimum reasonable nutrients content in the medium for the co-cultivation of soybean rhizobia with azospirills were identified. Data obtained can be used as the basis for optimization of culture media for co-cultivation of $B$. japonicum and $A$. brasilense. 